\title{
CRESCIMENTO E PARTIÇÃO DE ASSIMILADOS EM CULTIVARES DE ARROZ DIFERINDO NO POTENCIAL DE PRODUTIVIDADE DE GRÃOS $\left({ }^{1}\right)$
}

\author{
ANTELMO RALPH FALQUETO $\left({ }^{2}\right)$; DANIELA CASSOL $\left({ }^{2}\right)$; ARIANO MARTINS DE MAGALHÃES JÚNIOR $\left({ }^{3}\right)$; \\ ANTÔNIO COSTA DE OLIVEIRA $\left({ }^{4}\right)$; MARCOS ANTONIO BACARIN $\left({ }^{*}\right)$
}

\begin{abstract}
RESUMO
Foram estudados o crescimento, a partição de assimilados e a produção de grãos nas cultivares de arroz BRS Pelota (maior produtividade) e BRS Firmeza (menor produtividade). O experimento foi realizado em casa de vegetação, com plantas cultivadas em vaso. Utilizou-se o delineamento experimental inteiramente casualizado, com duas cultivares, nove coletas e quatro repetições por tratamento. Com a cultivar BRS Pelota houve maior acúmulo de matéria seca total $\left(W_{t}\right)$, principalmente no fim do ciclo, bem como maior área foliar $\left(\mathrm{A}_{\mathrm{f}}\right)$. A matéria seca alocada para o colmo + bainha e às panículas também foi maior em BRS Pelota. Porém, a porcentagem de $W_{t}$ destinada às panículas aos 125 DAE foi semelhante entre as cultivares. Em BRS Firmeza, o aumento em $W_{t}$ nas raízes pode ter influenciado o direcionamento de fotoassimilados para os grãos e contribuído para o atraso na senescência das plantas. A produtividade de BRS Pelota foi maior que a de BRS Firmeza (17,4 contra 11,8 g por vaso) e seu número de panículas por planta por vaso foi três vezes superior em relação à cultivar BRS Firmeza. O componente de produção de maior expressão no rendimento foi o número de panículas. A maior produtividade da cultivar BRS Pelota pode estar relacionada à maior área foliar e sua duração, o que permite o fornecimento de elevada quantidade de fotoassimilados por um período maior.
\end{abstract}

Palavras-chave: matéria seca, análise de crescimento, área foliar, BRS Firmeza, BRS Pelota.

\section{ABSTRACT \\ GROWTH AND ASSIMILATES PARTITIONING IN RICE CULTIVARS DIFERING IN GRAIN YIELD POTENTIAL}

The growth, assimilate partitioning and grain yield in BRS Pelota (high yield) and BRS Firmeza (low yield) rice cultivars were evaluated. The experiment was conducted in greenhouse (Department of Botany, Federal University of Pelotas) with complete randomized design composed by two cultivars, nine plant sampling times and four replicates. BRS Pelota rice cultivar exhibited higher accumulation of total dry matter $\left(\mathrm{W}_{\mathrm{t}}\right)$, mainly at the end of life cicle, as well as higher leaf area $\left(\mathrm{A}_{\mathrm{f}}\right)$. The dry matter allocated toward culm + sheath and panicles was higher in BRS Pelota. However, the $W_{t}$ percentage accumulated in panicles at 125 DAE was the same between cultivars. In BRS Firmeza the increase in $W_{t}$ in the roots may had influenced photoassimilates partitioning toward grains, and also contributed to delay of in plant senescence. Grain yield was higher in BRS Pelota than in BRS Firmeza (17.4 versus 11.8 g vaso), and also panicle number was three times greater in relation to BRS Firmeza. The yield component which exhibited higher relevance for productivity was the panicle number. The higher grain yield of BRS Pelota could be related to higher leaf area and leaf area duration, which allows the provision of elevated quantity of photoassimilates during longer period time.

Key words: Dry matter, growing analysis, leaf area, BRS Firmeza, BRS Pelota.

( $\left.{ }^{1}\right)$ Recebido para publicação em 15 de abril de 2008 e aceito em 7 de abril de 2009.

$\left(^{2}\right)$ Laboratório de Metabolismo Vegetal, Departamento de Botânica, Instituto de Biologia, Universidade Federal de Pelotas, 96010-900 Pelotas (RS). E-mail: bacarin@ufpel.edu.br $\left(^{*}\right)$ Autor correspondente.

$\left(^{3}\right)$ Empresa Brasileira de Pesquisa Agropecuária, Embrapa Clima Temperado, 96001-970 Pelotas (RS).

$\left({ }^{4}\right)$ Laboratório de Genômica e Fitomelhoramento, Faculdade de Agronomia Eliseu Maciel, Universidade Federal de Pelotas, 96010-900 Pelotas (RS). 


\section{INTRODUÇÃO}

A análise de crescimento é um método que descreve as mudanças na produção vegetal em função do tempo, e propõe-se a acompanhar a dinâmica da produção fotossintética avaliada por meio do acúmulo de matéria seca, o que não é possível com o simples registro do rendimento (RODRIGUES et al., 1993; URCHEI et al., 2000). Constitui-se em um dos primeiros passos na análise da produção primária de uma cultura (KVET et al., 1971). Pereira e Machado (1987) afirmam que a análise de crescimento representa a referência inicial na avaliação de produção das espécies vegetais, requerendo informações que podem ser obtidas sem a necessidade de equipamentos sofisticados. Tais informações são a quantidade de material contido na planta toda e em suas partes (folhas, caules, raízes e grãos) e o tamanho do aparelho fotossintetizante (área foliar), obtidos em intervalos de tempo regulares durante o desenvolvimento fenológico da planta (URCHEI et al., 2000). Neste contexto, a análise do crescimento pode ser utilizada para avaliar: adaptação ecológica das plantas a novos ambientes, competição interespecífica, efeitos de sistemas de manejo, modificação do regime de irradiância, tratamento com elicitores e fungicidas, além de permitir avaliação da capacidade produtiva de diferentes genótipos (SANTOS e COSTA, 1995; BACARIN et al., 1997; França et al., 1999; AntoniazZi e Deschamps, 2006).

Recentemente, a produtividade contrastante observada entre diferentes genótipos de arroz tem sido justificada por meio das diferenças na dinâmica da distribuição de assimilados entre órgãos durante o crescimento e o desenvolvimento das plantas (NTANOS e Koutroubas, 2002). Essa distribuição de fotoassimilados entre órgãos pode ser alterada durante o enchimento dos grãos e as limitações no ganho de biomassa podem ocorrer em um dado momento do desenvolvimento da planta (CRUZAGUADO et al., 2001). Em arroz, o padrão de distribuição de matéria seca ao longo do período de desenvolvimento das plantas foi descrito por SANTOS e Costa (1995), França et al. (1999) e Ntanos e Koutroubas (2002). Pelos resultados destes estudos, constatou-se que a produção de matéria seca e a translocação de fotoassimilados contribuíram significativamente para o desenvolvimento dos grãos em diferentes cultivares. Além disso, variações nestes parâmetros de translocação foram muito evidentes entre plantas pertencentes às subespécies índica e japonica, revelando maior produção de matéria seca e maior mobilização dos fotoassimilados em cultivares caracteristicamente de ciclo longo (Ntanos e Koutroubas, 2002).
O objetivo deste trabalho foi estudar, comparativamente, características de crescimento e de partição de assimilados em cultivares de arroz (BRS Pelota e BRS Firmeza) com produtividade contrastante.

\section{MATERIAL E MÉTODOS}

Foram estudadas duas cultivares de arroz, BRS Pelota (indica) e BRS Firmeza (japonica tropical), com distinta capacidade de produção de grãos. BRS Pelota é uma cultivar originária de plantas selecionadas de uma população heterogênea da cultivar gaúcha BRIRGA 410. Compõe-se de alta capacidade de perfilhamento e alto potencial produtivo $\left(10 \mathrm{t} \mathrm{ha}^{-1}\right)$. A cultivar BRS Firmeza é originária de cruzamento múltiplo realizado na Embrapa Clima Temperado, Pelotas-RS, pertencente ao grupo de plantas moderno/americano. Com pouca capacidade de perfilhamento, caracteriza-se também por seu fenótipo stay green e a produtividade próxima de $7,5 \mathrm{t} \mathrm{ha}^{-1}$ (Magalhães Júnior et al., 2003).

O experimento foi instalado em casa de vegetação, onde a temperatura média do ar foi, em média, de $30{ }^{\circ} \mathrm{C}$, densidade de radiação fotossinteticamente ativa, medida às $9 \mathrm{~h}$, igual a $460 \mu \mathrm{mol} \mathrm{m} \mathrm{m}^{-2} \mathrm{~s}^{-1}$ e regime de irrigação controlado (reposição automática de água por aspersão). Vinte e cinco sementes de cada cultivar foram semeadas em vasos plásticos com capacidade para 12 litros, preenchidos com solo fertilizado, de acordo com as normas técnicas para o cultivo do arroz no Estado do Rio Grande do Sul (SosbaI, 2007). Após a emergência das plantas, quando em $50 \%$ das plântulas havia o coleóptilo exposto acima do solo, realizou-se um desbaste, permanecendo uma planta por vaso. O delineamento experimental utilizado foi o inteiramente ao acaso, com duas cultivares, nove coletas e quatro repetições por tratamento.

As amostragens iniciaram-se ao $14^{\circ} \mathrm{DAE}$, correspondente, de acordo com a escala de COUNCE et al. (2000), ao estádio de crescimento $V_{2}-V_{3}$ e foram repetidas em intervalos regulares de 14 dias até o fim do ciclo $\left(R_{8}\right)$. As amostragens consistiram na determinação da área foliar e matéria seca de cada parte da planta. Em cada coleta, as plantas foram separadas em parte aérea (lâminas foliares verdes, lâminas foliares senescentes, colmo mais bainha e panículas) e raiz.

A área foliar das lâminas verdes $\left(\mathrm{A}_{\mathrm{f}}\right)$ foi estimada utilizando-se um medidor de área foliar marca LICOR (Modelo Li-3100). Para a determinação da matéria seca, as amostras de raiz, colmo mais bainha, lâminas foliares verdes, lâminas foliares senescentes e panículas foram acondicionadas em 
sacos de papel e levadas à estufa à temperatura de $70{ }^{\circ} \mathrm{C}$, onde foram mantidas por 72 horas.

Os dados primários de matéria seca total $\left(\mathrm{W}_{\mathrm{t}}\right)$ foram ajustados pela equação logística $W_{t}=W_{m}$. (1 $\left.+B e^{-C t}\right)^{-1}$, sendo $W_{t}$ a variável dependente; $W_{m}$ a estimativa assintótica do crescimento máximo; $\mathrm{B}$ e C as constantes de ajustamento; e a base natural de logarítimo neperiano e t o tempo após a emergência, em dias (RICHARDS, 1969). Para os valores primários de área foliar, o ajuste das equações foi realizado empregando-se polinômios ortogonais, elegendo-se o polinômio que melhor se ajustasse aos valores observados de $A_{f}$ (Richards, 1969). Os valores instantâneos da taxa de produção de matéria seca da parte aérea $\left(C_{t}\right)$ e da taxa de produção de área foliar $\left(C_{a}\right)$ foram determinados por meio da derivada da equação ajustada da matéria seca e da área foliar, em relação ao tempo respectivamente (RADFORD, 1967; RichARDS, 1969). Os valores instantâneos da taxa de crescimento relativo da parte aérea $\left(R_{\mathrm{w}}\right)$ e da taxa de crescimento relativo da área foliar $\left(R_{a}\right)$ foram obtidos pelas fórmulas $R_{w}=C_{t} \cdot W_{t}^{-1}$ e $R_{a}=C_{a} \cdot A_{f}^{-1}$. A estimativa dos valores instantâneos da taxa assimilatória líquida $\left(E_{a}\right)$ foi feita utilizando-se os valores de $C_{t}$ e $A_{f}$, através da equação $E_{a}=C_{t}$. $A_{f}^{-1}$. A razão de área foliar $\left(\mathrm{F}_{\mathrm{a}}\right)$, a razão da massa foliar $\left(\mathrm{F}_{\mathrm{w}}\right)$ e a área foliar específica $\left(S_{a}\right)$ foram determinadas a partir dos valores instantâneos de $\mathrm{A}_{\mathrm{f}}, \mathrm{W}_{\mathrm{t}}$ e $\mathrm{W}_{\mathrm{f}}$ (matéria seca das folhas), empregando-se as equações $F_{a}=A_{f}$. $\mathrm{W}_{\mathrm{t}}^{-1}, \mathrm{~F}_{\mathrm{w}}=\mathrm{W}_{\mathrm{f}} \cdot \mathrm{W}_{\mathrm{t}}^{-1}$ e $\mathrm{S}_{\mathrm{a}}=\mathrm{A}_{\mathrm{f}} \cdot \mathrm{W}_{\mathrm{f}}^{-1}$, de acordo com RADFORD (1967).

Ao término do experimento (125 DAE) foram determinados o número de panículas por planta, a produtividade de grãos por vaso, a massa de mil grãos em cada uma das cultivares. Submeteram-se esses resultados à análise de variância (ANOVA), e quando os valores de $\mathrm{F}$ foram significativos, realizou-se um teste de médias Tukey a 5\% de probabilidade.

\section{RESULTADOS E DISCUSSÃO}

Com o acúmulo de matéria seca total $\left(\mathrm{W}_{\mathrm{t}}\right)$ em relação às mudanças ontogenéticas, observou-se que as diferenças entre as cultivares aumentaram ao longo do ciclo de desenvolvimento das plantas e revelou comportamento logístico para ambas as cultivares (Figura 1a). BRS Pelota e BRS Firmeza tiveram crescimento lento na fase inicial do desenvolvimento (até aproximadamente 42 DAE - estádios V7-V8), seguida por uma fase de rápido crescimento até 83 DAE $\left(R_{3}-R_{4}\right)$ em BRS Firmeza e 97 DAE em BRS Pelota $\left(R_{5}-R_{6}\right)$ (Figura 1a). Essas variações na produção biológica entre as cultivares certamente refletem a duração do ciclo de desenvolvimento das plantas, como observado por SANTOS e CosTA (1995), em plantas de arroz de sequeiro cv. Araguaia e Guarani, de ciclos médio e precoce respectivamente. Até os $83 \mathrm{DAE}$, as diferenças no acúmulo de matéria seca total entre BRS Pelota e BRS Firmeza foram praticamente inexistentes. A partir desse período, as diferenças em $W_{t}$ entre as cultivares passaram a ser maiores, tornando-se muito evidentes no fim do ciclo (125 DAE).

A taxa de produção de matéria seca $\left(C_{t}\right)$ (Figura 1b) avalia o crescimento do vegetal relacionando a quantidade de material orgânico acumulado graças à área de solo disponível por unidade de tempo (SAntos e Costa, 1995). Assim, diferenças distintivas entre as cultivares estudadas com relação à $C_{t}$ foram: a) o tempo em que cultivares atingiram o ponto máximo de $C_{t}$, o qual, para BRS Pelota, foi prolongado por 15 dias em relação à cv BRS Firmeza e b) o valor máximo $C_{t}$, cujo valor foi superior para a cv. BRS Pelota. Se, por um lado, a taxa máxima de produção de matéria seca ocorreu aos 70 DAE em BRS Firmeza, como reflexo do seu ciclo de desenvolvimento curto, por outro, a maior produção de perfilhos, característica morfológica distintiva em BRS Pelota, pode fornecer uma justificativa plausível para o seu valor máximo superior de $\mathrm{C}_{\mathrm{t}}$.

$\mathrm{Na}$ taxa de crescimento relativo da parte aérea $\left(\mathrm{R}_{\mathrm{w}}\right)$, expressão do incremento de massa seca em relação à biomassa preexistente, observou-se declínio sistemático no acúmulo de matéria seca em ambas as cultivares ao longo do desenvolvimento fenológico das plantas (Figura 1c). Porém, até 56 DAE, foram observados maiores valores de $R_{w}$ na cultivar BRS Pelota, indicativo de maior eficiência de conversão de matéria seca nesta cultivar. Este resultado, entretanto, foi completamente revertido a partir desse período de desenvolvimento até aproximadamente 110 DAE (Figura 1c). Reduções em $R_{w}$ foram também observadas ao longo do desenvolvimento de plantas sorgo (BACARIN et al., 1997), feijão (URCHEI et al., 2000) e de cevada (Antoniazzi e Deschamps, 2006). Reduções em $R_{\mathrm{w}}$ são geralmente associadas ao acúmulo contínuo de matéria seca no decorrer do desenvolvimento e pelo declínio da capacidade relativa das plantas em produzir nova biomassa (Antoniazzi e Deschamps, 2006). Prováveis elevações na atividade respiratória ao longo do desenvolvimento fenológico, bem como o auto-sombreamento, cuja importância aumenta com a idade da planta, têm sido apontadas também como causas da redução nos valores de $R_{\mathrm{w}}$ (URCHEI et al., 2000). Além disso, na fase final do ciclo de desenvolvimento das plantas, o crescimento torna-se negativo em função da morte de folhas e gemas e aumento gradual de tecido nãoassimilatório (Milthorpe e MOORbY, 1974). 

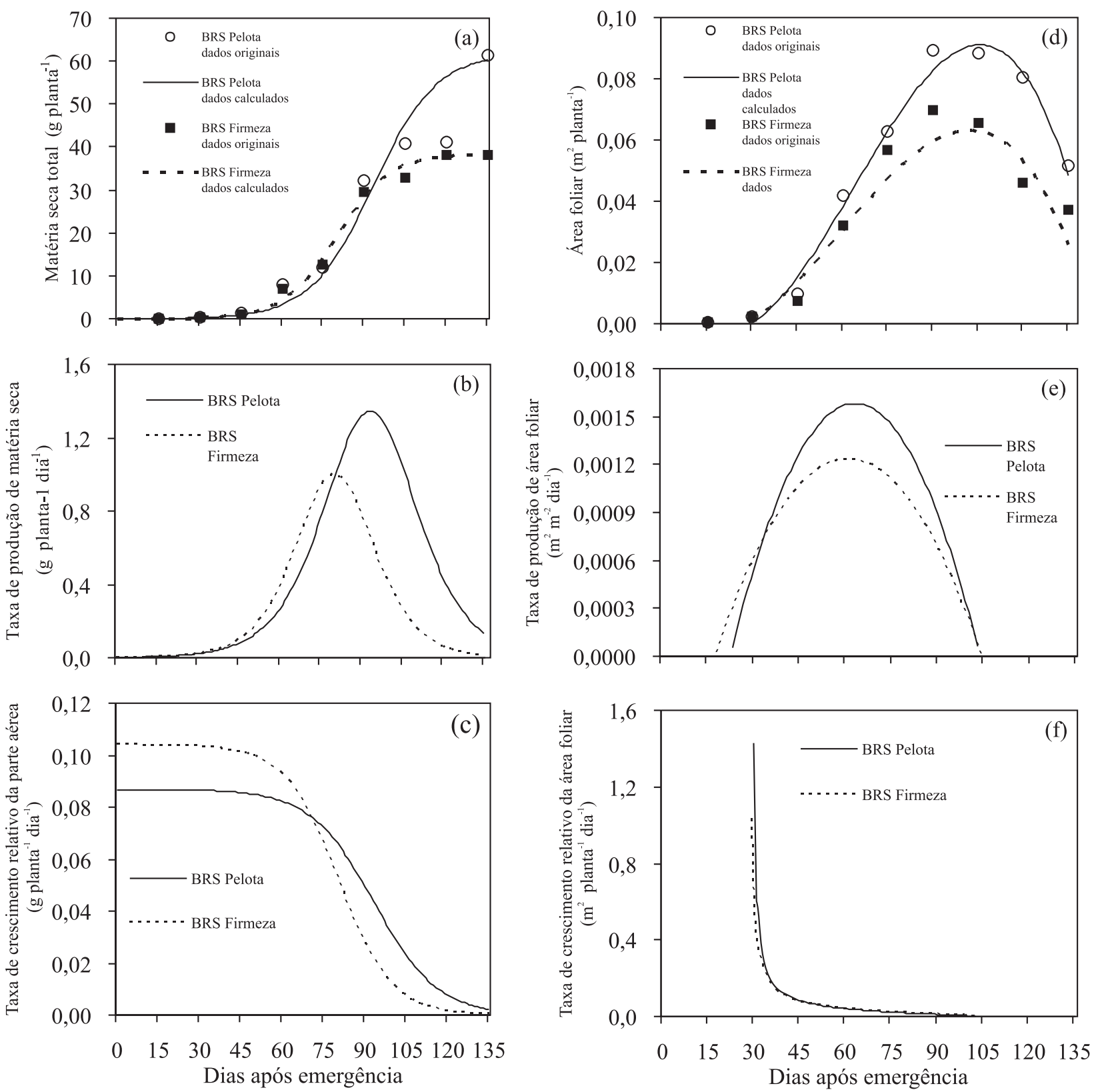

Figura 1. Matéria seca total $\left(W_{t}-a\right)$, taxa de produção de matéria seca $\left(C_{t}-b\right)$, taxa de crescimento da parte aérea $\left(R_{w}-\right.$ $c)$, área foliar $\left(A_{f}-d\right)$, taxa de produção de área foliar $\left(C_{a}-e\right)$ e taxa de crescimento relativo da área foliar $\left(R_{a}-f\right)$ de plantas de arroz cv. BRS Pelota (maior produtividade) e BRS Firmeza (menor produtividade).

Por conseguinte, ambas as cultivares atingiram área foliar $\left(\mathrm{A}_{\mathrm{f}}\right)$ máxima aos 97 dias após a emergência. Porém, uma área fotossinteticamente ativa superior foi obtida na cultivar BRS Pelota (Figura 1d). Após esta fase, observou-se redução em $A_{f}$ em ambas as cultivares, reflexo do estádio de desenvolvimento das plantas, uma vez que, a partir dos $97 \mathrm{DAE}$, as plantas estavam no estádio inicial de enchimento dos grãos (grãos em estado leitoso, ou $R_{5}-R_{6}$ ) e as folhas mais velhas, em processo de senescência. Nas cultivares de cevada BRS 195 e BRS 225, respectivamente, de ciclos longo e curto, Antoniazzi e Deschamps (2006) observaram valores de $\mathrm{A}_{\mathrm{f}}$ máximos aos $70 \mathrm{DAE}$, período coincidente ao estádio de emborrachamento das plantas.

A taxa de produção de área foliar $\left(\mathrm{C}_{\mathrm{a}}\right)$, a qual revela a velocidade de crescimento das folhas ao longo do ciclo de desenvolvimento da planta, atingiu seus valores máximos aos 56 DAE (estádio $\mathrm{V}_{9}-\mathrm{V}_{10}$ ), em ambas as cultivares, com posterior declínio (Figura 1e) e as curvas da taxa de crescimento relativo da área 
foliar $\left(R_{a}\right)$ expuseram valores decrescentes no decorrer do desenvolvimento das plantas (Figura 1f). Os maiores valores de $R_{a}$ foram obtidos na fase inicial de crescimento das folhas, tanto em BRS Pelota quanto em BRS Firmeza. Embora nessas cultivares tenha havido o mesmo desempenho ao longo do ciclo, em BRS Pelota o valor máximo foi de $R_{a}$ em torno de 1,4 $\mathrm{m}^{2} \mathrm{~m}^{-2} \mathrm{dia}^{-1}$ e em BRS Firmeza, aproximadamente, de $1,0 \mathrm{~m}^{2} \mathrm{~m}^{-2} \mathrm{dia}^{-1}$.

A taxa assimilatória líquida $\left(E_{a}\right)$ expressa o balanço entre a fotossíntese e a respiração da planta e descreve a eficiência da produção líquida do aparelho fotossintético, ou, em outras palavras, o incremento de biomassa por unidade de área foliar e de tempo (Watson, 1952, Netto et al., 2000). No período inicial do ciclo de vida das plantas, $\mathrm{E}_{\mathrm{a}}$ apresentou valores elevados em ambas as cultivares, especialmente em BRS Pelota (Figura 2a). Estes resultados refletem a menor área foliar existente e, em contrapartida, a elevada capacidade fotossintética dessas folhas jovens, estando de acordo com os resultados de Antoniazzi e Deschamps (2006) em plantas de cevada cvs. BRS 195 e BRS 225.

De forma geral, constatou-se que o comportamento de ambas as cultivares de arroz em relação à $E_{a}$ foi semelhante ao longo do desenvolvimento das plantas (Figura 2a), exceto no que se refere ao aumento em $\mathrm{E}_{\mathrm{a}}$ observado no início do período reprodutivo.

Nesta fase, as diferenças no ciclo foram expressivas e refletiram o aumento antecipado da taxa assimilatória líquida na cultivar BRS Firmeza, de ciclo curto (Figura 2a). Entretanto, os valores de $E_{a}$ no início e no fim do ciclo de desenvolvimento das plantas foram muito próximos e consistentes com os resultados observados em cevada (ANTONIAZZI e Deschamps, 2006), indicando que a menor duração do ciclo da cultivar BRS Firmeza pode ser compensada pelo maior investimento em arquitetura foliar.

As curvas da razão de área foliar $\left(F_{a}\right)$ evidenciaram aumento acelerado durante o período de crescimento vegetativo (Figura 2b), ou seja, até 42 DAE $\left(\mathrm{V}_{7}-\mathrm{V}_{8}\right)$, em ambas as cultivares, indicando que, nessa fase, a maior parte do material fotossintetizado é convertida em folhas, para maior captação da radiação solar disponível (URCHEI et al., 2000). A partir desse período, observaram-se decréscimos com a idade das plantas, decorrentes do surgimento de tecidos e estruturas não assimilatórias, além do autossombreamento, senescência e queda de folhas.
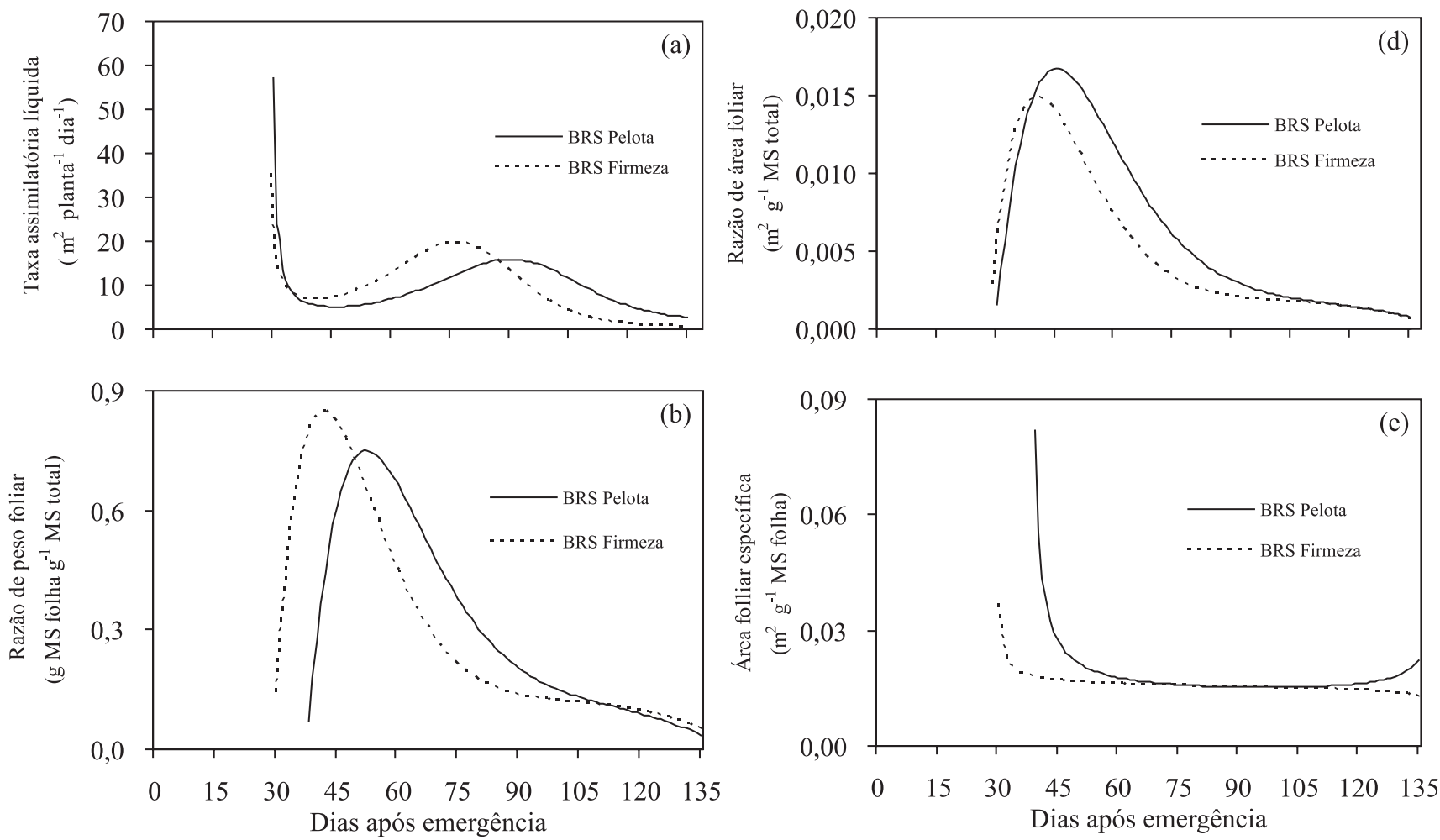

Figura 2. Taxa assimilatória líquida $\left(E_{a}-a\right)$, razão de área foliar $\left(F_{a}-b\right)$, razão da massa foliar $\left(F_{w}-c\right)$ e área foliar específica $\left(S_{a}-d\right)$ de plantas de arroz cv. BRS Pelota (maior produtividade) e BRS Firmeza (menor produtividade). 
Entretanto, as cultivares BRS Pelota e BRS Firmeza diferiram com relação ao valor máximo de $\mathrm{F}_{\mathrm{a}}$, bem como no tempo em que elas atingiram esses valores. $\mathrm{Na} \mathrm{cv}$. BRS Pelota, o incremento nos valores de $F_{a}$ foi maior e prolongado por pelo menos cinco dias em relação à cultivar BRS Firmeza. Esses resultados são, aparentemente, contraditórios aos observados para $W_{t}$ e $A_{f}$ (Figuras 1a,d), pois verificouse uma inversão, ou seja, enquanto $R_{a}$ decresceu após $42 \mathrm{DAE}, \mathrm{A}_{\mathrm{f}}$ e $\mathrm{W}_{\mathrm{t}}$ aumentaram neste mesmo período, resultados também observados por URCHEI et al. (2000) em cultivares de feijoeiro. Estes autores atribuíram a redução em $F_{a}$ à maior eficiência das folhas em converter energia luminosa e $\mathrm{CO}_{2}$ em matéria seca.

Observou-se, também, aumento na razão da massa foliar $\left(\mathrm{F}_{\mathrm{w}}\right)$ aos $42 \mathrm{DAE}\left(\mathrm{V}_{7}-\mathrm{V}_{8}\right)$ para a cultivar BRS Firmeza e aos 50 DAE $\left(\mathrm{V}_{9}-\mathrm{V}_{10}\right)$, aproximadamente, para BRS Pelota (Figura 2c). Aumentos em $\mathrm{F}_{\mathrm{w}}$ refletem maior alocação de assimilados para as folhas em desenvolvimento, tidas como dreno metabólico preferencial (ZEPKA, 2007). A partir desses períodos, os valores de $F_{\mathrm{w}}$ reduziram-se com a ontogenia das plantas, igualando-se no fim do período de florescimento com o início do enchimento dos grãos (100 DAE, aproximadamente, quando as plantas estavam no estágio de crescimento $\mathrm{R}_{5}-\mathrm{R}_{6}$ ). Tal redução observada ao longo do desenvolvimento das plantas foi consistente com os resultados descritos por LUGG e SinClair (1980), BACARIN et al. (1997), BRAGA (1998) e ZEPKA (2007). O decréscimo em $\mathrm{F}_{\mathrm{w}}$ ao longo do desenvolvimento das plantas reflete a mobilização de compostos fotoassimilados para outros órgãos da planta (LUGG e SinCLAIR, 1980).

Em relação à área foliar específica $\left(\mathrm{S}_{\mathrm{a}}\right)$ (Figura 2d), pôde-se observar que o comportamento das cultivares foi muito semelhante ao longo do desenvolvimento das plantas, com maiores valores de $S_{a}$ no início do ciclo da cultura. Os valores de $S_{a}$ foram decrescendo com o desenvolvimento das plantas de ambas as cultivares, de maneira similar ao decréscimo em $\mathrm{S}_{\mathrm{a}}$ observado por SILVA et al. (2005) em plantas de cana-de-açúcar. De acordo com esses autores, reduções em $S_{a}$ estão relacionadas à translocação de reservas das folhas para outras partes da planta, principalmente nos colmos, comportamento esse observado também por NeTTO et al. (2000), na cultura de batata com diferentes lâminas de irrigação. De acordo com RADFORD (1967), $S_{a}$ representa as diferenças no espessamento foliar, ou seja, permite verificar se as plantas estão acumulando fotoassimilados em suas folhas ou translocando-os para outros órgãos.

Avaliou-se também a distribuição de matéria seca entre os diferentes órgãos da planta, como mostra a figura 3. A matéria seca total acumulada foi igual a 7,87 e 6,87 g planta $^{-1}$ aos 60 DAE (quando as plantas estavam em crescimento vegetativo), 32,32 e 29,61 g planta $^{-1}$ no início da formação das panículas e 61,29 e 38,29 g planta $^{-1}$ na maturidade em BRS Pelota e BRS Firmeza, respectivamente. $\mathrm{O}$ aumento relativo no acúmulo de matéria seca durante o estádio de amadurecimento foi $48 \%$ em BRS Pelota e $23 \%$ em BRS Firmeza (Figura 3), mostrando que a cultivar BRS Pelota é muito mais eficiente no que se refere à produção e ao acúmulo de biomassa.

Houve também diferença entre as cultivares estudadas em relação ao padrão de distribuição de matéria seca em cada órgão durante o período de enchimento de grãos. A figura 3 mostra um aumento considerável na massa da matéria seca do colmo + bainha em BRS Pelota em detrimento à sua redução em BRS Firmeza. Por conseguinte, a matéria seca acumulada nas folhas reduziu-se em ambas as cultivares refletindo o crescimento negativo característico de plantas em estádio de maturação (Milthorpe e Moorby, 1974) e a distribuição de matéria seca para as panículas foi maior na cultivar BRS Pelota, de maior produtividade (Figura 3).

Embora se observem nas cultivares diferenças na produtividade, em termos de porcentagem de matéria seca destinada às panículas no fim do ciclo reprodutivo, notam-se valores muito semelhantes $(29 \%$ e $30 \%$ para BRS Pelota e BRS Firmeza respectivamente). Sabe-se que panículas e órgãos vegetativos como colmos, folhas e raízes constituem importantes drenos de fotoassimilados em arroz (KAтO et al., 2004). Em BRS Pelota, os colmos e as bainhas foram os maiores órgãos dreno para os fotoassimilados no decorrer do período de amadurecimento. Esse resultado é sustentado por meio do aumento no acúmulo de matéria seca observado nestes órgãos no fim da última coleta (estádio $\mathrm{R}_{8}$ ) (Figura 3a). Resultados semelhantes foram observados por KATO et al. (2004), estudando diferenças na distribuição de matéria-seca em plantas de arroz fêmea estéril. Estes autores verificaram que o surgimento de perfilhos tardios assumia o papel de novos órgãos dreno durante o estádio final de desenvolvimento das plantas. Geralmente, o surgimento de perfilhos tardios, originados de gemas laterais, está relacionado a uma elevada taxa de fotossíntese na fase final de enchimento dos grãos, mas a sua influência na distribuição de matéria seca ainda não foi estudada (TAKAHASHI, 1992). 
Por conseguinte, o aumento na massa da matéria seca das raízes em ambas as cultivares aos 125 DAE $\left(R_{8}\right)$ permite supor que novas raízes se desenvolveram ao longo do amadurecimento das plantas, como descrito por KATO et al. (2004). Essas raízes atuariam como órgãos dreno de fotoassimilados. É necessário salientar que, comparativamente à cv. BRS Pelota, o aumento da matéria seca nas raízes de BRS Firmeza mostrou-se mais evidente (Figura $3 b$ ).

Em termos de produtividade das cultivares, BRS Pelota teve um rendimento de grãos de 17,4 g vaso, significativamente superior ao rendimento da cultivar BRS Firmeza (11,8 g vaso) (Tabela 1). Os valores de produtividade obtidos no presente experimento são similares aos obtidos em condição de campo conforme descrito por Magalhaes Júnior et al (2003) e Sosbai (2007). Desta forma, BRS Pelota produziu, em média, $31 \%$ mais grãos que a cultivar BRS Firmeza. Além disso, o número de panículas em BRS Pelota foi aproximadamente duas vezes superior à cultivar BRS Firmeza, não havendo diferença significativa entre as cultivares com relação à massa de mil grãos.

Em BRS Firmeza, a produção de grãos foi positivamente relacionada com a massa de mil grãos e negativamente relacionada com o número de panículas. Nenhuma correlação significativa entre os componentes de produção foi observada para a cultivar BRS Pelota. GERALDO et al., (2000) verificaram que a produção de grãos em diferentes cultivares de milheto foi positivamente correlacionada com alguns componentes de produção, como a massa de mil grãos e o comprimento das panículas e negativamente correlacionada com o número de panículas. Esses resultados são consistentes com os obtidos para a cultivar BRS Firmeza. Assim, pode-se inferir que o componente de produção de maior expressão no rendimento das cultivares BRS Pelota e BRS Firmeza foi o número de panículas, o que comprova que a cultivar BRS Firmeza, por perfilhar menos (menos afilhos férteis) que a BRS Pelota, necessitaria de maior densidade de plantas $\mathrm{m}^{-2}$.

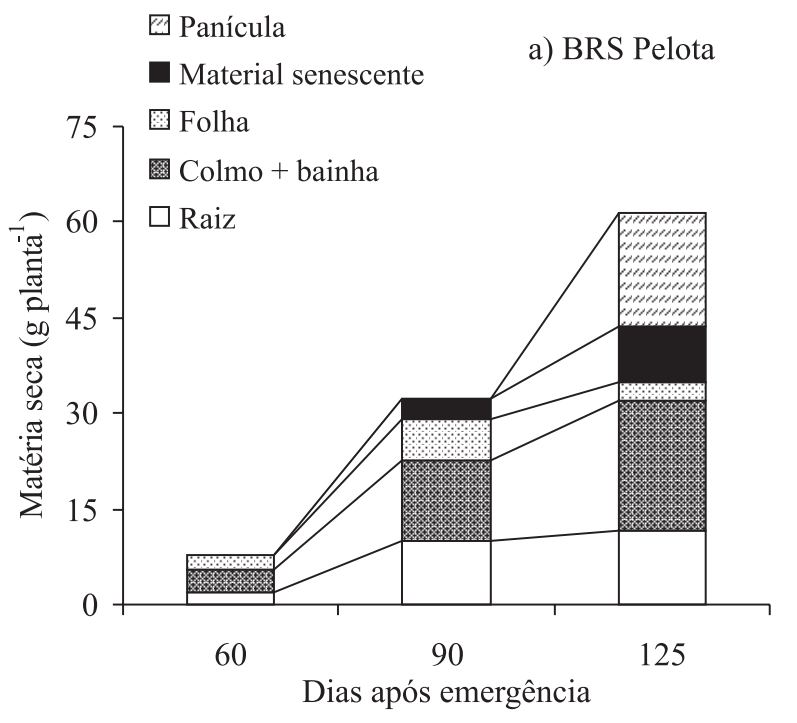

b) BRS Firmeza

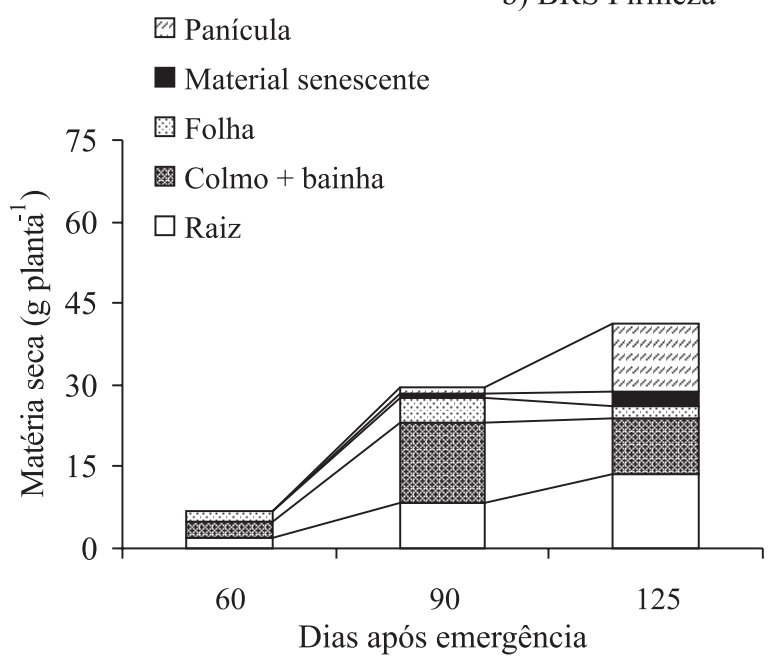

Figura 3. Distribuição de matéria seca entre órgãos de plantas de arroz cv. BRS Pelota (maior produtividade) e BRS Firmeza (menor produtividade), medida aos 60 dias após a emergência (crescimento vegetativo), 90 dias após a emergência (período de início de enchimento de grãos) e aos 125 dias após a emergência (período correspondente ao final de enchimento dos grãos).

Tabela 1. Produção de grãos, massa de mil grãos e número de panículas de plantas de arroz cv. BRS Pelota (maior produtividade) e BRS Firmeza (menor produtividade), obtidos aos 125 dias após a emergência, período correspondente ao final de enchimento dos grãos ${ }^{1}$. ( $\mathrm{CV}=$ coeficiente de variação $)$

\begin{tabular}{lccc}
\hline \multirow{2}{*}{ Variável } & \multicolumn{2}{c}{ Cultivar } & CV \\
\cline { 2 - 4 } & BRS Pelota & BRS Firmeza & $\%$ \\
Produção de grãos $\left(\mathrm{g} \mathrm{vaso}^{-1}\right)$ & $11,8 \pm 0,55 \mathrm{~b}$ & 5,4 \\
Massa de mil grãos $(\mathrm{g})$ & $17,4 \pm 2,98 \mathrm{a}$ & $27,0 \pm 0,06^{\mathrm{ns}}$ & 4,5 \\
Número de panículas por planta & $26,4 \pm 0,14^{\mathrm{ns}}$ & $3,0 \pm 0,00 \mathrm{~b}$ & 25,4 \\
\hline
\end{tabular}

Médias seguidas de letras distintas na linha diferem entre si pelo teste Tukey $(p \leq 0,05)$ 


\section{CONCLUSÕES}

1. A cultivar BRS Pelota proporcionou maior produção de matéria seca $\left(\mathrm{W}_{\mathrm{t}}\right)$ com maiores valores de taxa de crescimento $\left(C_{t}, R_{w}, C_{a}\right.$ e $\left.R_{a}\right)$, maior área foliar $\left(\mathrm{A}_{\mathrm{f}}\right)$ e maior taxa de assimilação líquida $\left(\mathrm{E}_{\mathrm{a}}\right)$, nas condições em que o estudo foi desenvolvido.

2. O aumento relativo no acúmulo de matéria seca durante o estádio de amadurecimento foi maior na cultivar BRS Pelota.

3. A cultivar BRS Pelota mostrou maior eficiência na produção e acúmulo de biomassa em órgãos da parte aérea, principalmente nos colmos + bainha e panículas.

4. A massa de mil grãos não diferiu entre as cultivares BRS Pelota e BRS Firmeza.

5. Comparativamente à cultivar BRS Firmeza, a produção de grãos em BRS Pelota foi $31 \%$ maior.

6. O componente de produção de maior expressão no rendimento das cultivares BRS Pelota e BRS Firmeza foi o número de panícula.

\section{REFERÊNCIAS}

ANTONIAZZI, N.; DESCHAMPS, C. Análise de crescimento de duas cultivares de cevada após tratamentos com elicitores e fungicidas. Ciência Rural, v.36, p.1065-1071, 2006.

BACARIN, M.A.; LOPES, N.F.; BENINCASA, M. Crescimento de sorgo sacarino, Sorghum bicolor (L.) Moench, cultivado em terrenos com diferentes exposições e declividades. 1. Análise de crescimento. Ciência e Agrotecnologia, v.21, p.286-293, 1997.

BRAGA, E.J.B. Crescimento do milho (Zea mays L.) inoculado com a bactéria Beijerinckia sp. como fonte de nitrogênio. 1998. 58f. Dissertação (Mestrado em Fisiologia Vegetal) - Instituto de Biologia, Universidade Federal de Pelotas, Pelotas.

COUNCE, P.A.; KEISLING, T.C.; MITCHELL, A.J. A uniform, objective, and adaptative system for expressing rice development. Crop Science, v.40, p.436-443, 2000.

CRUZ-AGUADO, J.A.; RODÉS, R.; ORTEGA, E.; PÉREZ, I.P.; DORADO, M. Partitioning and conversion of ${ }^{14} \mathrm{C}-$ photoassimilates in developing grains of wheat plants grown under field conditions in Cuba. Field Crops Research, v.69, p.191-199, 2001.

FRANÇA, M.G.C.; ROSSIELLO, R.O.P.;ZONTA, E.; ARAÚJO, A.P.; RAMOS, F.T. Desenvolvimento radicular e influxo de nitrogênio em duas cultivares de arroz. Pesquisa Agropecuária Brasileira, v. 34, p.1845-1853, 1999.

GERALDO, J.; ROSSIELLO, R.O.P.; ARAÚJO, A.P.; PIMENTEL, C. Diferenças em crescimento e produção de grãos entre quatro cultivares de milheto pérola. Pesquisa Agropecuária Brasileira, v.35, p.1367-1376, 2000.

KATO, M.; KOBAYASHI, K.; OGISO, E.; YOKOO, M. Photosynthesis and dry-matter production during ripening stage in a female-sterile line of rice. Plant Production Science, Tokyo, v.7, p.184-188, 2004.

KVET, J.; ONDOK, J.P.; NECAS, J.; JARVIS, P.G. Methods of growth analysis. In: SESTÁK, Z.; CATSKÝ, J.; JARVIS, P.G. (Ed.). Plant photosynthetic production: manual of methods. The Hague: W. Junk, 1971, p. 343-391.

LUGG, D.G.; SINCLAIR, T.R. Seasonal changes in morphology and anatomy of field grown soybean leaves. Crop Science, v.20, p.191-196, 1980.

MAGALHÃES JÚNIOR A.M. de; FAGUNDES, P.R.; FRANCO, D.F. Melhoramento genético, biotecnologia e cultivares de arroz irrigado. In: MAGALHÃES JÚNIOR de, A.M.; GOMES, A. da S. Arroz irrigado: melhoramento genético, manejo do solo e da água e prognóstico climático. Pelotas, RS: Embrapa Clima Temperado, p.13-33, 2003. (Embrapa Clima Temperado: Documentos, 113)

MILTHORPE, F.L.; MOORBY, J. An introduction to crop physiology. Cambridge, Grã-Bretanha : Cambridge University, 1974. 201p.

NETTO, A.O.A.; RODRIGUES, J.D.; PINHO, S.Z. Análise de crescimento na cultura da batata submetida a diferentes lâminas de irrigação. Pesquisa Agropecuária Brasileira, v.35, p.901-907, 2000.

NTANOS, D.A.; KOUTROUBAS, S.D. Dry matter and N accumulation and translocation for Indica and Japonica rice under Mediterranean conditions. Field Crops Research, v.74, p.93-101, 2002.

PEREIRA, A.R.; MACHADO, E.C. Análise quantitativa do crescimento de comunidades vegetais. Campinas: IAC, 1987, 33p. (IAC, Boletim técnico, 114)

RADFORD, P.J. Growth analysis formulase - their use and abuse. Crop Science, v.7, p.171-175, 1967.

RICHARDS, F.J. The quantitative analysis of growth. In: STEWARD, F.C. (Ed.). Plant Physiology. New York: Academic Press, 1969, p. 3-76.

RODRIGUES, J.D.; RODRIGUES, S.D.; PEDRAS, J.F.; DELACHIAVE, M.E.A.; BOARO, C.S.F.; ONO, E.O. Diferentes níveis de cálcio e o desenvolvimento de plantas de estilosantes (Stylosanthes guyanensis (AUBL.) SW. Cv. "Cook"). Scientia Agricola, v.50, p.166-175, 1993.

SANTOS, A.B; COSTA, J.D. Comportamento de variedades de arroz de sequeiro em diferentes populações de plantas, com e sem irrigação suplementar. Scientia Agricola, v.52, p.1-8, 1995.

SILVA, D.K.T.; DAROS, E.; ZAMBOM, J.L.C.; WEBER, H.; IDO, O.T.;ZUFFELLATO-RIBAS, K.C.; KOEHLER, H.S.; OLIVEIRA, R.A. Análise de crescimento em cultivares de cana-de-açúcar em Cana-Soca no Noroeste do Paraná na safra de 2002/2003. Scientia Agraria, v.6, p.47-53, 2005. 
SOCIEDADE SUL-BRASILEIRA DE ARROZ IRRIGADO (SOSBAI). Arroz irrigado: recomendações técnicas da pesquisa para o Sul do Brasil. Pelotas, RS: SOSBAI, 2007. 164p.

TAKAHASHI, K. Analysis of developmental phase of stem in high nodal-position tillers in rice plants. Japon Journal of Crop Science, Tokyo, v.61, p.49-55, 1992.

URCHEI, M.A.; RODRIGUES, J.D.; STONE, L.F. Análise de crescimento de duas cultivares de feijoeiro sob irrigação, em plantio direto e preparo convencional. Pesquisa Agropecuária Brasileira, v.35, p.497-506, 2000.

WATSON, D.J. The physiological basis of variation in yield. Advances in Agronomy, v.4, p. 101-145, 1952.

ZEPKA, A.P.S. Germinação, vigor de sementes e crescimento de plantas de trigo (Triticum aestivum L.) submetidas a diferentes doses de pendimethalin. 2007. 48f. Dissertação (Mestrado em Fisiologia Vegetal) - Instituto de Biologia, Universidade Federal de Pelotas, Pelotas. 